\title{
Enhancing Tourism Competitiveness of Hong Kong via Tourism Planning: A Comparative Case Study between Hong Kong and Singapore
}

\author{
Kaewta Muangasame $^{1}$ \& Siyathorn Khunon $^{2}$ \\ ${ }^{1}$ Tourism and Hospitality Management Division, Mahidol University International College, Thailand \\ ${ }^{2}$ International School of Tourism, Suratthani Rajabhat University, Thailand \\ Correspondence: Kaewta Muangasame, Tourism and Hospitality Management Division, Mahidol University \\ International College, Thailand. Tel: 66-8-1491-4230. E-mail: kaewta.mua@mahidol.ac.th
}

\author{
Received: July 5, 2013 Accepted: September 5, 2013 Online Published: November 29, 2013 \\ doi:10.5539/ass.v9n17p30 URL: http://dx.doi.org/10.5539/ass.v9n17p30
}

\begin{abstract}
This article aims to recommend tourism planning in Hong Kong (HK). A comparison case study of tourism planning between Singapore and Hong Kong is discussed. Secondary data from web sites, observations and in-depth interviews of ten residents and ten tourists was conducted to investigate tourism planning in the two countries. The study discloses that the HK government should consider adopting a long term oriented plan and implement an integrated approach with their tourism planning. Sustainability issues, land management and carrying capacity should be addressed by HK tourism planners. Lastly, re-structuring of the Tourism board should be considered to improve the efficacy of tourism planning of HK.
\end{abstract}

Keywords: tourism planning, policy, sustainable tourism policy and plan, Hong Kong, Singapore

\section{Introduction}

Recently, it is undeniable that tourism is a main tool to generate income in many countries. Tourism brings both advantages and disadvantages. In terms of advantages, tourism brings a great deal of cash flow, wealth, wages and jobs for local people. Concurrently, it also makes available modern decadences in tourism destination locations of both tangible and intangible things. Some tangible deteriorative effects are garbage, pollution of water, air, noise and degradation of views. The erosion of traditional cultures and conflicts among stakeholders are some examples of the intangible disadvantages from tourism. Therefore, tourism needs to be well-organized rather than just letting things develop in a happenstance manner (Inskeep, 1991). If tourism development is not well-organized, the detrimental effects on tourism destinations will be more severe than before.

It is very challenging for tourism planners to initiative a sufficient tourism plan. Owning to the fact that there are many factors and stakeholders involved in tourism planning. Some sufficient tourism plans cannot be implemented due to the intervention of political issues, which are notoriously difficult to solve. Many successful tourism plans are in countries with strong, stable governments such as Singapore, New Zealand, etc. However, only having a strong government may not support achievement of tourism plans. It is due to the fact that tourism planning is dealing with keeping a balance between national resources and various stakeholders' needs and wants. Benchmarking is a popular tool to sufficiently improve strategic management in an organization and a country. It is necessary for mutual learning by studying each other to enhance competitiveness of the individual nations (Wong et al., 2008). However, strategic information gathered from benchmarking should be applied based upon existing resources of the countries.

Hong Kong is a region with tourism as a strategic tool to generate income. The approximate annual growth rate of tourist arrivals is $10-15 \%$. However, it is still questionable as to whether or not tourism planning of Hong Kong is sufficient. Studying other countries with successful tourism plans in place may provide appropriate information for improvements.

This paper aims to propose how to enhance tourism competitiveness of Hong Kong (HK) via tourism planning by conducting a comparative case study. Tourism planning of Singapore (SG) is compared with that of Hong Kong to investigate the differences and similarities between government legislation, policies, strategies and plans 
of HK and SG. The strong and weak points within the tourism planning of the two countries will be analyzed. The well-organized tourism plan of Marina Bay Sand Resort will be assessed. Finally, all investigative information will be crystallized to give recommendations for improving Hong Kong tourism planning.

\section{Literature review}

\subsection{Tourism Planning Definitions}

The definition of tourism planning has been widely debated among academics and practitioners. However, it is vital to propose a clear definition to provide an adequate framework for analyzing and understanding the complex issues in tourism planning. Heretofore, planning will be defined as a process of forethought of decision-making that is a series of interdependent and systematically related decisions rather than the decisions of an individual (Hall, 2008, p. 8). Inskeep (1991) points out that at the beginning, tourism policy formation was rather spontaneous and often motivated by problems resulting from lack of planning and development controls. In addition, he also cites many cases in which various forms are suitable in a single country or region, depending on the specific resources, locations, tourist markets, tourism policies adopted and other factors involved. Goeldner et al. (2000) also define tourism policy as "a set of regulations, rules, guidelines, directives and development/promotion objectives and strategies that provide a framework within which the collective and individual decisions directly affecting tourism development and the daily activities within a destination are taken" (p. 1).

On the complexity of tourism policy, Hall (2008) points out that it is not straightforward to categorize borderline of the tourism product. Therefore, the overlapping when it needs to decide the appropriate policy for all. Tourism activity can have an effect on a group or location and this is when tourism policy issues matter the most at the destination management level (Weimer \& Vining, 2005).

\subsection{Tourism Planning Assessments}

There are many assessment methods available to evaluate the efficacy of tourism planning. Tourism planning is a strategic plan; therefore many academics figure out that vision, mission, objectives and strategies are applied to determine sufficient tourism planning (Wong et al., 2008; Ruhanen, 2004). Pearce (2000) analyzed the tourism planning of Samoa by being concerned with many aspects such as the conformity of objectives and policy, the structure of tourism organizations and development concepts. Additionally, goal attainment is also a good indicator of a sufficient tourism plan. Analyses of the mechanisms that drive the success of tourism planning (such as staffs and organizational structure) are also conducted to measure the quality of tourism planning (Pearce, 2000). Power of governments to implement the plan set is also a critical factor for successful tourism planning. Additionally, tourism stakeholders such as local people, business, non-profit organizations, etc. should be properly involved in the tourism planning process (Wong et al., 2008; Ruhanen, 2004). In addition, the precise measurements of tourism performance such as current visitor numbers, length of stay, spending and carrying capacity of tourism are applied to investigate well-organized tourism plans (Ruhanen, 2004).

\section{Methodology}

The paper conducts a qualitative research approach. The needed data was divided into two types: primary and secondary data. Primary data came from in-depth interviews and on-site observations. Secondary data came from the tourism plan of each country via websites, fliers, and newspaper articles. Data collection was conducted within 3 months starting from Singapore trip in October 2011 for one week and in Hong Kong afterward. In-depth interviews identified the perceptions of stakeholders on tourism planning focused on convenience sampling with ten residents and ten tourists from each country were collected by using open-ended questions in particular with local residents. However, tourists were selected in purposeful selection; all of them were required to visit both countries more than two times. In addition, touristic destinations were selected to find the informants. The saturation of data was reached between 9 to 10 respondents from both groups in this study. Souvenirs from Thailand were given after 20 minutes interview. On-site observations were conducted within one week from both destinations to gain more data of needed details to ensure the data collected was accurate. Content analysis was employed to interpret the data analysis by data coding using the key words into the table as separate topic sets under thematic and frequency approach from interview and secondary data sources. In conclusion, the data was interpreted according to the tourism planning and policy by Inskeep (1991) and Hall (2008). Validity and reliability were also concerned. To sum up the data collection process with validity concern, first, tape-recorded interviews were provided a concrete reference to the original source to verify any potential discrepancies. Second, the interviews were attempted to transcribe immediately after each interview. Third, the open-ended interview questions were developed in order to allow the participants to answer in an unconstrained way, to use as many words as they wish and to avoid bias from interviewers (Altinay \& Paraskevas, 2008). 
Fourth, triangulation of data sources and multiple analysts from two methods were adopted to strengthen the findings (Patton, 1990). In other words, to avoid author bias, and the effect of the researcher on the individual, member check, as Thai researchers with no preferences, was used to ensure the meaning of participants 'responses.'

\section{Results}

This study's aims are to analyze the strengths and weaknesses of the two countries plans and to examine and evaluate whether Hong Kong's current tourism planning approach is effective or not. This comparative case will identify Hong Kong and Singapore by using Inskeeps \& Hall as a guideline. The Tourism 21 blueprint of Singapore and Tourism Work plan 2011-2012 of Hong Kong were selected to identify as it can be seen in Table 1 and Table 2.

\subsection{Comparison of the Tourism Plans between Hong Kong and Singapore}

Table 1. A comparison of tourism plan between Hong Kong and Singapore

\begin{tabular}{|c|c|c|}
\hline Tourism planning & Singapore Tourism 21 blueprint & Hong Kong Tourism Board Workplan-2011-2012 \\
\hline Vision \& Strategic focus & $\begin{array}{l}\text { Vision: To be a destination of choice, a } \\
\text { powerful tourism hub attracting visitors, } \\
\text { businesses and talents from across the } \\
\text { world by } 2015 \\
\text { Strategic Focus: } \\
\text { 1. Strengthening Singapore's position as a } \\
\text { Leading Convention \& Exhibition City in } \\
\text { Asia with a strong and dynamic business } \\
\text { environment. } \\
\text { 2. Developing Singapore as a leading } \\
\text { Asian leisure destination by providing an } \\
\text { enriching experience that is Uniquely } \\
\text { Singapore. } \\
\text { 3. Establishing Singapore as the Services } \\
\text { Centre of Asia a place where visitors come } \\
\text { to enjoy high-end quality services such as } \\
\text { healthcare and education services. }\end{array}$ & $\begin{array}{l}\text { Vision: To establish and promote Hong Kong as Asia's } \\
\text { premier international city, a world-class destination for leisure } \\
\text { and business visitors. } \\
\text { Strategic Focus: } \\
\text { 1. Strengthen Hong Kong's Destination Image-Adopt New } \\
\text { Thematic Marketing Platform 'Hong Kong Asia's World City' } \\
\text { 2. Enrich Annual Events Calendar } \\
\text { 3. Change Mix of Marketing Communication with Increased } \\
\text { Focus On Digital Marketing and PR to Maximize Reach and } \\
\text { Impact. } \\
\text { 4. Re-align Multi-destination Development \& Promotion } \\
\text { Strategy by Focusing on Pan-Pearl River Delta Provinces. } \\
\text { 5. Grow MICE Business } \\
\text { 6. Build Cruise Demand } \\
\text { 7. Enhance Business-Building Capabilities Through Effective } \\
\text { Trade Support and Partnership Programmes } \\
\text { Uphold Quality Assurance and Organizational Excellence } \\
\text { (Includes strengthening promotion of the Quality and Honest } \\
\text { Hong Kong Tours Programme and the Quality Tourism } \\
\text { Services Scheme) }\end{array}$ \\
\hline Purpose of tourism planning & & \\
\hline $\begin{array}{l}\text { 1. Enhance visitor } \\
\text { satisfaction } \\
\text { 2. Improved economy \& } \\
\text { business success }\end{array}$ & $\begin{array}{l}\text { 1. }++ \\
\text { 2. }+++ \\
\text { 3. }+++\end{array}$ & $\begin{array}{l}1 .+ \\
2 .+++ \\
3 .+\end{array}$ \\
\hline $\begin{array}{l}\text { 3. Protection of resources } \\
\text { 4. Community \& area } \\
\text { integration }\end{array}$ & 4. ++ & 4.+ \\
\hline $\begin{array}{l}\text { Dimension of Tourism } \\
\text { planning }\end{array}$ & & \\
\hline $\begin{array}{l}\text {-government } \\
\text {-economic } \\
\text {-environment } \\
\text {-Community based } \\
\text {-sustainable tourism }\end{array}$ & $\begin{array}{l}\text {-Combination of all of dimension, } \\
\text { government lead to achieve economic, } \\
\text { environment, sustainable tourism from the } \\
\text { UN initiative project (A 21). }\end{array}$ & $\begin{array}{l}\text {-Government led the plan by considering } \\
\text { economic schemes. Environment and } \\
\text { community have focus in Master' plan, } \\
\text { not particularly in tourism planning. }\end{array}$ \\
\hline $\begin{array}{l}\text { Structure-tourism } \\
\text { government body\& National } \\
\text { Focal point for sustainable } \\
\text { development }\end{array}$ & $\begin{array}{l}\text {-National focal point for sustainable } \\
\text { development by Ministry of the } \\
\text { Environment and Water Resources }\end{array}$ & $\begin{array}{l}\text {-National focal point for sustainable tourism development by } \\
\text { Environmental Management Division, Department of } \\
\text { Regional Economy National Development and Reform } \\
\text { Commission }\end{array}$ \\
\hline
\end{tabular}


Table 2. Comparative case study of Hong Kong and Singapore tourism planning and policy

\begin{tabular}{l}
\hline Hong Kong \\
\hline \\
1. Strengthen economic lead in dimension of tourism plan. \\
2. Focusing on visitor satisfaction and improvement. \\
3. Clear visionary in leading Asia's World city, in \\
performance of improved economy \& business success. \\
4. Established appropriate experience for visitors concerning \\
new emerging market and repeat visitor.
\end{tabular}
Singapore

1.Clear vision of becoming a tourism capital-tourism business center.

2. Integrated dimension of tourism-government, economic, environment, community and sustainability.

3. Enhance visitor satisfaction by developing high-end quality service in health and educational experience.

4.Improving economy and business to all stakeholders

5. The balance of "Green and Clean" concept can be defined by the relationship with environment and local quality life improvement.

6. From the organizational chart, it is referring the good model, good infrastructure in terms of understanding the nature of tourism business and trends in the future.

7. It is appropriate for both people and management with clear direction, responsible roles and the future development for long term plan strategy.

8. The clustering zone for tourism plan development such as heritage zones, business zones were based on the future oriented creativity.

9. Long term oriented plan.

10. Well-organized land and fundamental facilities such as water, energy.

1. Balancing of the tourism development and sustainability or environmental relationship direction.

2. Unclear strategic focus between economic or tourism plan. Most of objectives, are related to increasing investment.

3. No focus of protection of resources \& community integration from strategic tourism plan.

4. Only focus international tourist, nor domestic market.

5. Marketing approach in tourism plan are tactics to support new promotional events, not in the strategic plan level.

5. From the organizational Chart, there are some overlapping responsibilities, which will be difficult to work out without conflicts and confusion.

6. No indicators for outcomes in case of failure \& misconception during implementation.

7. Short term oriented plan.

1. Loss of country identity by shifting into "New-Asia-Singapore"

2. Local factors are less detailed in tourism plan such as exotic, multi-cultural experiences

3. Quality service developed only in particular products

4. Ascetic government rules can influence the image of the country in the long term.

5. Long term plan strategies need to be flexible to accept unpredictable events and public opinion changes.

According to Table 1 and Table 2, from analyzing the tourism plans, there are several factors determining the achievement of Singapore tourism as follows:

\subsubsection{Governments' Authority}

Government policies in many countries wreak havoc on tourism businesses by failing in tourism management. Therefore, government policy is a critical factor influencing successful tourism planning. A positive example can be found in Singapore where tourism is and has been systematically developed as seen by the many new attractive destinations as well as the many new projects being developed. Marina Bay Sand, for example, is a new mega-project in Singapore, which can lure a great number of tourists to visit SG. It is due to the Singapore has political stability and is a strong authority in managing the country. Furthermore, every project's master plan has been developed even though the government has changed. Continuation of the set projects is very crucial to improve the efficacy of tourism and provide benefits to the country. Importantly, the Singapore government precisely knows the needs and wants of its stakeholders, which lead it to wisely balancing everyone's requirements. The SG government has a clear understanding of themselves; what the strengths and weaknesses 
of the country are leading to continuously seeking improvements. Consequently, the country attracts many huge foreign investors.

\subsubsection{Conformity of Tourism Planning}

Singapore's tourism plan addresses every aspects of the country: the social-culture, economics, education, environmental factors and fundamental infrastructures that serve both hosts and guests. It appears that Singapore's tourism planning uses a systematic approach in which all elements relating to tourism is simultaneously developed. National policy development of Singapore integrated all environments: education, economic, businesses, international businesses and local people to support the tourism policy as well as its vision of a tourism plan. Therefore, tourism planning of Singapore is both internal and external conformity.

\subsubsection{Tourism Planning Approaches and Long-Term Oriented Plan}

Interestingly, Singapore and Hong Kong competed against each other to be the number one world hub business center. Straightforward economic development seems to be their future direction. Singapore has applied a resource driven, integrative approach. While HK tourism planning relies on market driven factors. However, an increasing number of tourist arrivals are main indicators for both of them. In fact, appropriate tourism plan dimensions should integrate both economic and sustainability as in, for example, New Zealand. The vision of New Zealand as created in the strategic tourism plan for 2015 which states that "tourism is valued as the leading contributor to a sustainable New Zealand Economy" with two approaches; Kaitiakitanga' means guardianship, care and protection. It provides a basis for the approach to sustainability managing New Zealand's natural and cultural environment for current and future generations; and 'Manaakitanga' which means sharing exceptional and natural hospitality, knowledge and beliefs, on the basis of mutual respect between host and visitor, (New Zealand Tourism. govt, 2011). The Strategy contains 92 recommended actions grouped into four themes, therefore, it can be analyzed that the tourism plan of New Zealand has been created with the support of all the stakeholders, not just one dimension. It reflects how government pays attention to "togetherness" concept with local residents. The plan also shows that a thriving domestic market is also important. In reality, domestic travel keeps many tourism businesses going, and it helps tourism operators develop and refine new products before launching them in the international markets. Therefore, the tourism plan needs to emphasize a balance between domestic and international markets.

\subsection{Tourism Performance}

Sufficient tourism planning can be determined by tourism performance, which is measured from key stakeholders as residents and tourists.

\subsubsection{Reflective Tourism Planning from Hong Kong and Singapore Residents}

Residents of both Hong Kong and Singapore are positive about tourism plans organized by their governments. The positive perception comes from already being well-established in business tourism and from being a shopping and dining destination. In addition, the transportation system and the integration of tourism related facilities are mentioned as having a positive impact in the survey results. However, negative perception is concerned with the misconception of mass-tourism development against the sustainable tourism approach. HK residents recommended some areas in need of improvement in HK tourism, which ranged from improvement of service quality of retailers including honesty, creating a positive atmosphere, and lastly, the need to monitor the number of inbound tourists as it brings negative impacts to the social life of HK residents. This negative perception, thus, reflects the insufficient performance of HK tourism planning. Therefore, future plans of the HK government need to pay more attention to resident perceptions.

Conversely, Singaporeans are more positive than Hong Kong residents with no comments in the area of negative perceptions. They perceived Singapore as one of the best places: a world-class tourism destination that is safe, clean, with a variety of cultures. Singapore has set a new benchmark for the international tourism industry. The latest integrated resort leads: Resort World and Marina Bay Sand. These perceptions illustrate the sufficient tourism planning of the SG government. However, there are some areas in need of improvement such as: room rates, encouraging exploration of other parts of the country, and more advertising in foreign countries.

\subsubsection{Reflective Tourism Planning from Hong Kong and Singapore Tourists}

HK tourism planning has been successful in convenient transportation, shopping and dining. Most tourists select HK for its short travel distance, many good attractions, easy and inexpensive shopping and mixed-culture. The destinations to recommend were ranked from Disneyland, The Peak and Ocean Park. All of interviewees said they would visit Hong Kong again as it's a short haul trip, they enjoyed the shopping and the variety of food and the transportation convenience. It is notable that the HK government may consider initiating more new 
attractions.

While SG provides new fantastic attractions; it is an expensive destination. Thus, the perceptions illustrate that SG has developed its tourism products continuously. The purpose of traveling to Singapore was varied, such as willing to experience something new, business trips, educational tours and a short break from time constraints. The places to recommend are ranked from Night Safari, Universal Studio and Merlion. On the other hand, the least recommended places are Merlion following by Julong Park and SG 200. It seems that the old attractions were recently replaced by new ones. Interestingly, there were a few people who proposed not return to Singapore due to its high cost, small landmark with less attractions and the high exchange rate. On the other hand, most tourists are willing to go back for experiencing new attractions.

The comparative opinions between both countries in tourism development have been addressed as follows: Singapore has built many new attractions for the returning tourist and both countries are developing fast. Lastly, Singapore is strict but safer than Hong Kong. For improvement, more affordable hotels, more friendly and polite staff, density of used land with more infrastructures has been criticized. In addition, Singapore has a more sustainable concept, using a green approach which is reflected in its long term plan, Hong Kong is more convenient but Singapore is more organized.

\subsection{A Case Study: Best Planning Practice of Marina Bay Sand, Singapore}

In this case, Marina Bay Sand has been selected due to its well-organized plan. Analysis is based on the author's observations and limited secondary data. The study is divided into three areas: design considerations, development standards, and creation of a sense of place. Firstly, design consideration. It can be seen that the architectural design has integrated a combination of hi-class resort with a natural, friendly environment.

In the case of inclusion of local design, Marina Bay is less detailed in pinpointing how typical local cultures are expressed in the resort design. This point was asked during the seminar with the answer being that Singapore is a business oriented destination and that the design reflects the uniqueness of Singapore's business approach. Additionally, there are no uses of local building materials as all resources and materials were imported from other neighboring countries. And the designer who created this project was American and the consultation team members were also Westerners, with only a few Singaporeans. Therefore, the resort itself failed to show details of Singaporean cultures and its identity.

With regards to the environmental relationship, in this area the government plays an important role by creating strict, sustainable policies to regulate new hotel development and to ensure compliance with the law. Landscape has been criticized in two ways both positive and negative sides, as it was located in the harbor with the top view in Singapore. However, the huge building closing to harbor cannot protect the unpredictable events from the sea such as Tsunami. In addition, the high level of sea, which is slightly increasing every year even though the quality systematic barrages, is being arranged.

According to the development standard and what the authors observed on-site, the building and surroundings are built together with the appropriate density (used area: 249,843 sq.m). The height of building is $207 \mathrm{~m}$. with 57 stores. One challenge in construction was the tower that slopes at an incline. Unsupported, it could buckle under its own weight. The sloping leg induces an enormous external force onto the structure, which needed to be addressed during construction, (Safdie, 2011). Interestingly, the entire complex sits on 0.56 million square meters (6 million square feet) of reclaimed land-sand infill on deep soft marine clay deposits. Marina Bay is a former salt water estuary that is now a fresh water reservoir. Prior to excavation, the site needed to be reinforced. In order to do this 1.5 meter thick ( 5 feet) steel-reinforced concrete diaphragm walls (coffer dams of up to 120 meters or 394 feet in diameter) were extended 50 meters (164 feet) into the ground providing an enclosure for excavation, (Safdie, 2011). The Parking areas are designed to avoid the conditions of new ground with the strong weight in long term. The Marina Bay Sand is a huge building in a separate zone. It can be criticized at this point that it is not easy to walk from one end of the hotel to the other. As Ap (2003) mentions that the size and providing fun and lively experiences for customers' needs to be considered in appropriate planning as well as easy to manage for all implementation.

Lastly, creating a sense of place is also important. The architectural style of this building was designated to make a significant piece of art on earth. The combination of nature with high technology, a huge, elegant stance with the best view in Singapore is integrated for making Marina Bay Sand different. A unique natural setting came from the feeling of walking in a National park with a green atmosphere surrounded by huge trees. The hotel has created memorable experiences by using both internal and external factors. Internal experiences came from the helpful staff who gave a massive amount of information about the hotel without tiring. It simply brought memorable moments during visiting. To be critical, the directional signage is not clear while walking inside. Therefore, it would be easy to waste time by getting lost and creating confusion and frustration for the guests. The main target market of the Marina Bay Sands is the business traveler and time is valuable to them. As result, providing more information centers and professional guides or private butler services is recommended. Cultural 
diversity of history is rarely found in the building. Hough (1995) determines good site design by using the three principles of Process, Diversity and Connectedness. In using the criteria above Marina Bay Sand has achieved process of planning site with sustainable design, which combined all linkages of significant theme in tourism with environmental relationships. However, the authenticity in culture is less emphasized in the building itself but is separately expressed in the Art Science Museum. This is targeted at international travelers who want to see exhibitions from the most renowned collections in the world, not only Singaporean culture and authenticity. Therefore, it can be argued that Marina Bay Sand missed the authenticity of its destination as understanding of local place are required in planning, not only the economic, social and political context in connectedness (Hough, 1995, p. 24). Hall (2001) states that fakery is the replication of environmental and social meaning through the manipulation of appearances, actions or experiences. In the case of Marina Bay Sand providing the advertised Sampan Rides to enjoy the sensation of being gently paddled around in a beautifully-crafted Chinese wooden boat, the fakery emerged out for authenticity including unclear positioning of its Singapore culture could be disconnected with tourist experience and expectation. In other words, the activities and decorations have no linkages to the culture except, grand, modern, and high technology.

\section{Recommendations for Hong Kong Tourism Planning}

Hong Kong's tourism planners should create a long-term orientated plan but be flexible as time and situations changed. Having a long-term plan gives clear direction and convinces stakeholders of the validity of the plan. Furthermore, many things may need a long time to prepare or construct such as airports, filtered seawater plants, roads, etc. Lastly, a long-term plan can provide internal conformity among sub-projects to achieve the vision set. In addition, fundamental facilities such as water should be not neglected. While, Singapore developed the best model for water plants reducing water supply from outside, the construction of the desalination plant in Hong Kong is on hold and relies on the more expensive water from Mainland China. An integrated approach should be applied to create harmony among other plans or external plans such as educations, technologies, zoning, etc.

The integrated approach should be applied in tourism planning of HK. Additionally, sustainable tourism development should be started in Hong Kong as the United Nations have initiated the NSTD implementation and provided clear guidelines. The economic tourism plan approach may not remain in changeable situation. Therefore, it is time to emphasize a more sustainable tourism plan with a strategic focus rather than only the number of tourist arrivals and the reputation as an excellent center for business which economically driven. Historic sites should be promoted and developed rather than discarded. For example, many traditional Chinese buildings in the Soho area were replaced with a modern building with 25 stories (Yang, 2011). While, Singapore has put more effort into preserving and promoting their cultural heritage buildings whereas, Hong Kong has tried to construct more modern buildings.

Land needs to be well organized. It is due to there are many areas in Hong Kong needing proper development from the HK government. Tai Wo, for example, has high potential to be a natural and historical tourism destination if it is appropriately developed. This district has both natural destinations such as mountains and waterfalls and traditional Chinese houses. However, it is still neglected. Zoning issues should also be of concern. All requirements of stakeholders should be considered in regards to dealing with zoning of the land. In fact, if the government has a long-term oriented plan, a result is that the zoning areas can be easily set. In contrast, Singapore can simultaneously manage land, tourism, business and local people's needs.

Local residents play an important role in influencing tourism planning. As summarized in the survey, the residents in Hong Kong found that the capacity of Hong Kong is getting less and therefore the government needs monitor the number of inbound tourists as unregulated growth brings negative impact on the social life of HK residents. Therefore, carrying capacity should be addressed in tourism planning. Mainland Chinese are the greatest number of tourist arrivals to Hong Kong. As a result, all HK destinations are crowded and have long queues. Consequently, it may cause Westerners or nearby tourists to escape to other destinations if the HK government cannot deal with excess capacity.

Regionalization and tourism do not always enjoy a mutually beneficial relationship, (Chang, 1998). He argued that the tourism development of Singapore is required to emphasize the need of local factors with was challenged by the geographic constraints of the site and the lack of natural attractions; limited market base and investment opportunities within Singapore; the need of quality of life to Singaporeans and the goal of goodwill with neighboring countries are criticized in the long term strategy. Therefore, the HK government should also aware of this issue in tourism planning due to having the similar limitations with SG.

Re-structuring of Hong Kong's tourism organization(s) is recommended. The Singapore models are clearly defined and separate responsibility into various sectors such as corporate development, regional development, and sector development. It is well-organized structure and covers all aspects in tourism development. The strength of Singapore is that it is well known as a proactive and forward-looking country and is reflective how well prepared the country is. New strategies that have been criticized in the international conference have already 
become part of the national tourism organization such as Change management, Plan analysis and integration, Crisis management, Resource development with knowledge management. Currently, Singapore is the only Asian country to have the Tourism Satellite Account (TSA) providing a consistent and coherent standard of measure of the economic contribution of tourism industry (Yeoh et al., 2002).

\section{References}

Altinay, L., \& Paraskevas, A. (2008). Planning research in Hospitality and Tourism. London, Butterworth-Heinemann.

Ap, J. (2003). Basic Principles of Planning. Handout: Tourism Policy, Planning \& Development.

Chang. (1998). Regionalism and tourism: exploring integral links in Singapore. Asia Pacific Viewpoint, 39(1), 73-94. http://dx.doi.org/10.1111/1467-8373.00054

Goeldner, C. R., Ritchie, J. R. B., \& McIntosh, R. W. (2000). Tourism Principles, Practices and Philosophies (8th ed.). New York: John Wiley \& Sons.

Hall, C. (2001). Trends in ocean and coastal tourism: The end of the last frontier? Ocean \& Coastal Management, 44(9-10), 601-618. http://dx.doi.org/10.1016/S0964-5691(01)00071-0

Hall, C. (2008). Tourism Planning: Policies, Processes \& Relationship (2nd ed.). Harlow, UK: Prentice Hall.

Henderson, C. (2004). Destination Development: Singapore and Dubai Compared. Journal of Travel and Tourism Marketing.

Henderson, J. (2004). Paradigm shifts: National tourism organizations and education and healthcare Tourism: The case of Singapore. Tourism and Hospitality Research, 5(2), 170-180. http://dx.doi.org/10.1057/palgrave.thr.6040016

Hong Kong Tourism Commission. (2011). Organization Chart. Retrieved February 28, 2012, from http://www.tourism.gov.hk/english/about/abt_org.html

Hough, M. (2004). Cities and Natural processes: A basic of sustainability. Rougtledge. New York.

Inskeep, E. (1991). Tourism Planning, An Integrated and sustainable development approach. Singapore, John Wiley \& Sons.

Marinabaysands.com. (2011). About Marina Bay Sands. Retrieved February 28, 2012, from http://www.marinabaysands.com/Company-Information/About-Singapore/

Pearce, D. G. (2000). Tourism plan reviews: Methodological considerations and issues from Samoa. Tourism Management, 21, 191-203. Pland.gov.hk. Sustainable Development for Hong Kong. Retrieved February 28, 2012, from http://www.pland.gov.hk/pland_en/p_study/comp_s/susdev/report/e_sustai.html http://dx.doi.org/10.1016/S0261-5177(99)00048-5

Ruhanen, L. (2004). Strategic planning for local tourism destinations: An analysis of tourism plans. Tourism and Hospitality Planning \& Development, 1(3), 239-253. http://dx.doi.org/10.1080/1479053042000314502

Safdie, M. (2011). Marina Bay Sands, Singapore. Retrieved February 28, 2012, from http://www.ctbuh.org/TallBuildings/FeaturedTallBuildings/MarinaBaySands/tabid/1766/language/en-US/De fault.aspx

Tourism Strategy Group. (2010). New Zealand Tourism Strategy 2015. Retrieved February 28, 2012, from http:/www.tourism.govt.nz/Our-Work/New-Zealand-Tourism-Strategy-2015/

United Nation. (2007). Division for Sustainable Development, National Information-Singapore. Retrieved February 28, 2012, from http://www.un.org/esa/agenda21/natlinfo/countr/singapor/index.html

Weimer, D., \& Vining, A. (2005). Policy Analysis: Concepts and Practice (4th ed.). Upper Saddle River, New Jersey, Prentice Hall.

Wong, E. P. Y., Bauer, T. G., \& Wong, K. K. F. (2008). A critical comparison of tourism policies of Hong Kong and Singapore: An avenue to Mutual Learning. International Journal of Tourism Research, 10, 193-206. http://dx.doi.org/10.1002/jtr.656

Yang, I. (2011, October 28). Save SOHO. HK Magazine, 4.

Yeoh, B., Ser, T., Wang, J., \& Wong, T. (2002). Tourism in Singapore: An Overview of Policies and Issues. Tourism Management and Policy, World Scientific Publishing Co. Ltd.

\section{Copyrights}

Copyright for this article is retained by the author(s), with first publication rights granted to the journal.

This is an open-access article distributed under the terms and conditions of the Creative Commons Attribution license (http://creativecommons.org/licenses/by/3.0/). 